\title{
LÓGICA E CIÊNCIA COGNITIVA: O PSICOLOGISMO CONTRA-ATACA ${ }^{1}$
}

Marcos Barbosa de OLIVEIRA2

- RESUMO: O objetivo do trabalho é apresentar o contexto histórico, as motivações e um esboço de alguns resultados de uma pesquisa ainda não concluída. Primeiro fala-se um pouco da Ciência Cognitiva - de suas características gerais, de sua história, de sua relação com a Epistemologia. Considera-se depois sua relação com a Lógica, emergindo daí uma concepção da Lógica como descritiva e mentalista. Esta concepção choca-se com o antipsicologismo de Frege. A meta da pesquisa é refutar os argumentos de Frege enquanto objeções à tese de que existem duas lógicas, ambas mentalistas, uma descritiva e outra normativa.

- UNITERMOS: Lógica; Ciência Cognitiva; psicologismo; Frege; normatividade; mentalismo; platonismo.

O objetivo deste texto é apresentar o contexto histórico, as motivações e um esboço de alguns resultados de uma pesquisa ainda não concluída.

Quanto ao contexto histórico, seu principal elemento é o impacto que o surgimento da Ciência Cognitiva está causando na Filosofia - em particular na Epistemologia e na Filosofia da Mente. A Ciência Cognitiva é ainda pouco conhecida no Brasil; nos Estados Unidos e Reino Unido, particularmente, ela constitui uma disciplina já bem estabelecida, havendo departamentos, cursos, associações e revistas especificamente dedicados a ela. A Ciência Cognitiva entrou em cena há cerca de 30 anos, como resultante da confluência de vários fatores, sendo os principais o surgimento da Inteligência Artificial, o reconhecimento do fracasso do behaviourismo como estratégia de pesquisa em Psicologia, e as revolucionárias contribuições de Chomsky para a Lingüística.

Duas boas introduções, cada uma a seu modo, a esta debutante no elenco das disciplinas, ou áreas do saber humano, são Matter and consciousness, de Paul Churchland e The mind's new science: a history of the cognitive revolution, de Howard

1. Comunicação apresentada no III Encontro Nacional de Filosofia promovido pela ANPOF e realizado em Gramado (RS) de 5 a 8 de setembro de 1988.

2. Departamento de Filosofia da Educação e Ciências da Educação - USP- 05508 - SP. 
Gardner. Teremos que nos limitar aqui a indicar apenas alguns dos aspectos fundamentais da Ciência Cognitiva.

A Ciência Cognitiva é mentalista, no sentido de que admite a postulação de entidades e processos mentais para explicar os fenômenos cognitivos - e nisso ela se opõe ao behaviourismo, tanto na Psicologia quanto na Filosofia - e é materialista, rejeitando todas as formas de dualismo e de idealismo.

Uma das características mais marcantes da Ciência Cognitiva é sua natureza multidisciplinar: ela engloba e articula problemas, conceitos, teorias e métodos de inúmeras áreas do saber: da Epistemologia da Lógica e da Filosofia da Mente, da Psicologia Cognitiva, da Inteligência Artificial, da Lingüística, da Neurociência, da Teoria da Evolução e da Antropologia. A relação precisa de cada um desses campos com a Ciência Cognitiva varia naturalmente de caso para caso. O aparecimento da nova disciplina está provocando alterações na divisão territorial do saber, mas a situação por enquanto é muito fluida: as fronteiras mudam rapidamente, umas idéias ganham terreno enquanto outras recuam, idéias novas entram em campo a todo momento. É inútil nesta conjuntura tentar traçar um mapa definitivo; minha convicção entretanto é de que tal mapa mostrará, quando a poeira tiver assentado, uma importante região tendo sido conquistada pela Ciência Cognitiva, um domínio com forte coesão interna, bem mais que uma simples associação de subáreas vinculadas a outros domínios.

No que se refere à Epistemologia, uma tática na tentativa de resistir aos avanços da Ciência Cognitiva consiste em enfatizar a diferença de posturas. A manobra é sintetizada nas seguintes colocações: a Epistemologia é uma disciplina normativa, seus pronunciamentos referem-se a princípios e critérios cuja função, em última análise, é prescrever aquilo em que devemos acreditar. Em relação a cada uma das ciências, a Epistemologia tem o papel de legislador; ela não pode, portanto, sob pena de circularidade, valer-se dos resultados de nenhuma delas. Na medida em que se coloca como uma disciplina científica, a Ciência Cognitiva é, para a Epistemologia, apenas uma ciência entre outras tantas, devendo, como estas, submeter-se a suas normas.

A réplica consiste na reafirmação da relevância da Ciência Cognitiva para a Epistemologia, sendo plenamente assumida a circularidade invocada acima. Para legislar sobre o conhecimento é preciso primeiro estudá-lo descritivamente, determinar suas origens, suas formas de representação, seus processos e mecanismos de desenvolvimento etc. Este estudo cabe à Ciência Cognitiva; ela não pode realizá-lo sem adotar, pelo menos implicitamente, certas normas da Epistemologia, porém o círculo assim formado não é vicioso, e é de qualquer maneira inevitável. A aceitação desta inevitabilidade é decorrência do reconhecimento do fracasso do projeto cartesiano que dominou a Epistemologia a té poucas décadas atrás: o projeto de estabelecer uma Filosofia Primeira que constituísse o fundamento, os alicerces de todo o conhecimento. Este fracasso está documentado, de maneira a meu ver definitiva, no clássico "Epistemologia naturalizada", de Quine (1981). 
Quine aliás merece um comentánio especial quando se fala em Ciência Cognitiva. Há, por um lado, uma concordância muito grande entre a Epistemologia Naturalizada proposta por ele e a Ciência Cognitiva que se faz hoje, particularmente no que se refere às relações com a Epistemologia Tradicional. Mas há, por outro, uma diferença básica, decorrente da oposição entre a orientação behaviourista da Epistemologia Naturalizada de Quine e o decidido mentalismo da Ciência Cognitiva. Outra diferença é que, como já foi observado, apesar de conceder à Epistemologia o direito de recorrer a resultados da Psicologia, e de outras ciências particulares, Quine não se vale deste direito: quando efetivamente se dedica à Epistemologia Naturalizada (por exemplo, em Word and object e Roots of reference), ele se deixa guiar principalmente por predileções filosóficas a prion, fazendo muitas vezes afirmações conflitantes com resultados bem confirmados da Psicologia empírica.

Mas voltemos ao ponto que estávamos discutindo, o das relações entre Ciência Cognitiva e Epistemologia. Uma demonstração mais direta da relevância daquela para esta pode ser formulada se se pensar a Epistemologia não a partir de uma caracterização abstrata, mas como uma tradição que se desenvolve ao longo da história. $O$ fato é que na obra de autores consagrados paradigmaticamente como espistemólogos - filósofos como Descartes, Hume, Kant e tantos outros - são abordados problemas pertencentes ao estudo descritivo do conhecimento, tratados cientificamente na Ciência Cognitiva. Para dar apenas um exemplo, se bem que um dos mais importantes, basta lembrar o problema das origens do conhecimento, da secular controvérsia sobre o caráter inato ou adquirido do conhecimento humano. Como ilustração do tratamento científico atual desta questão, pode-se citar, entre muitas publicações, o debate entre Piaget e Chomsky no volume editado por Piattelli-Palmarini (1983).

Na medida em que a Ciência Cognitiva se caracteriza como o estudo do conhecimento, ela não pode deixar de se interessar pela Lógica. As relações lógicas são articulações entre proposições, e proposições constituem o substrato, a forma de representação em que o conhecimento se corporifica. ${ }^{3} \mathrm{~A}$ Lógica é imprescindível para a investigação sobre a estrutura do conhecimento, e sobre como ele se desenvolve já um dos processos de desenvolvimento consiste em inferências, e inferências são estudadas na Lógica.

3. Se as proposições são a única forma de representação, ou se outras formas são possiveis, esta é uma das questões centrais da Ciência Cognitiva. Como diz Gardner, "o debate teórico contemporâneo entre os cientistas cognitivos de carteininha em certo sentido não passa de uma discussão sobre as melhores maneiras de conceituar as representações mentais. Alguns pesquisadores são de opinião que há uma única forma de representação mental (em geral, uma forma em que figuram proposições ou enunciados); alguns acreditam em pelo menos duas formas de representação mental, uma mais semelhante a uma figura (picture), a outra mais próxima a proposições; outros ainda crêem que se pode postular múltiplas formas de representação mental, sendo impossivel determinar qual é a correta (1985, p. 39-40).

A partir desta passagem pode-se afirmar que nenhum cognitivista nega serem as proposiçōes uma forma de representação. 
Essas considerações conduzem à seguinte idéia: não seria a Lógica na verdade parte da Ciência Cognitiva? Quem se propõe a defender tal tese confronta-se imediatamente com um sério problema. Colocando-se como ciência, a Ciência Cognitiva atribui-se uma natureza factual, descritiva - por oposição à normativa ou prescritiva - e esta característica deve necessariamente pertencer também a cada uma de suas partes. Ou seja, uma Lógica concebida como parte da Ciência Cognitiva seria uma Lógica descritiva. Isto por um lado; por outro, dado o mentalismo da Ciência Cognitiva, teríamos que postular uma Lógica mentalista - ou seja, uma Lógica que tomasse entidades e processos mentais como sua referência última. Ora, esta concepção descritiva e mentalista da Lógica é fundamentalmente idêntica à concepção psicologista que Frege criticou com tanto sucesso.

Tão definitiva pareceu esta vitória do antipsicologismo de Frege que esta postura logo se estabeleceu em outras áreas da Filosofia. Pode-se questionar que parcela de responsabilidade cabe a Frege por isso, mas o fato é que nota-se na Filosofia do século $\mathrm{XX}$ uma grande vaga de antipsicologismo, visível particularmente na tradição a que pertencem o Círculo de Viena e Popper, bem como na tradição fenomenológica de Husserl. Giedymin dá um bom retrato da situação na seguinte passagem:

(...) no período do entre guerra (...) havia uma fortíssima reação antipsicologista entre os filósofos com inclinação para a Lógica, que neste caso encontravam-se numa aliança única e algo estranha com os discípulos de E. Husserl, o arqui-antipsicologista. Tratava-se originalmente de uma reação contra a interpretação mentalista-psicológica das leis da Lógica. Havia entretanto um ressentimento tão forte contra o psicologismo, que mesmo no campo da metodologia científica quaisquer considerações que fossem além de relações entre sentenças eram desencorajadas e consideradas como de algum modo inferiores a considerações puramente lógicas; problemas e conceitos pragmáticos transformavam-se em lógicos, isto é, sintáticos, embora isto nem sempre fosse fácil ou satisfatório. Parece-me que muitas passagens de Logik der Forschung, e de outras obras contemporâneas testemunham este conflito entre um antipsicologismo extremado e a vontade de levar em consideração componentes pragmáticos da ciência, tais como atitudes, decisões etc. (1968, p. 74-5)

Na fase subseqüente da tradição lógico-positivista/popperiana há um rompimento deste logicismo caracterizado por Giedymin. A abertura entretanto não é na direção da Psicologia, mas sim da História e da Sociologia, sendo Kuhn o marco principal desta inflexão. A Epistemologia transforma-se cada vez mais em Filosofia da Ciência; a perspectiva cartesiana centrada no sujeito é substituída pela visão do conhecimento como processo social e histórico.

Se o antipsicologismo nesta vertente tornou-se implícito, o mesmo não acontece com a linhagem mais ou menos contemporânea de filósofos cujas preocupações concentram-se na linguagem: é enfático, militante mesmo, o antipsicologismo do Wittgenstein da segunda fase, de Ryle, Quine e muitos outros.

Uma das conseqüências da vitória do antipsicologismo de Frege foi, parece, a de que precisamente este aspecto de sua obra tem sido relativamente pouco explorado e discutido. É como se a própria absorção generalizada do antipsicologismo pela comunidade, sua transformação de questão polêmica em terreno comum, tivesse 
neutralizado o interesse pelo tópico. É sintomático, por exemplo, que na antologia de textos filosóficos de Frege editada por Geach and Black (1977), os extratos do prefácio das Grundgesetze omitam precisamente a parte referente ao psicologismo. A seguinte passagem de Susan Haak, em Philosophy of logics, também é ilustrativa desta tendência, embora já representando uma reação a ela:

Embora tenha havido uma época em que era bastante comum supor que os princípios da Lógica são leis do pensamento, a vigorosa crítica de Frege foi tão influente que tem havido muito pouco apoio ultimamente para o psicologismo de qualquer tipo ou espécie. Suspeito entretanto que os argumentos de Frege contra o psicologismo são menos conclusivos, e que pelo menos alguma forma de psicologismo é mais plausivel do que é moda hoje em dia supor. Uma reavaliação cabal do psicologismo exigiria entretanto uma exposição mais completa e sofisticada do que posso apresentar sobre a natureza do pensamento; o que se segue é portanto, na melhor das hipóteses, apenas um esboço. (1978, p. 238)

O aparecimento da Ciência Cognitiva nesta conjuntura pode ser visto, em certa medida, como uma revanche do psicologismo. Em certa medida apenas, pois, há uma considerável diferença entre a Ciência Cognitiva de hoje e o psicologismo do fim do século passado contra o qual Frege batalhou - e se assim não fosse, não se justificaria a revanche. Mas quanto aos aspectos fundamentais - quanto ao mentalismo e à postura descritiva - a Ciência Cognitiva é sem dúvida a herdeira do antigo psicologismo.

Mas voltemos à idéia de que a Lógica deve ser vista como parte da Ciência Cognitiva. Diante do quadro descrito acima, a jogada mais óbvia de quem quisesse defendê-la seria procurar uma refutação das teses de Frege que estabelecesse sua negação mais simples, ou seja: a Lógica é, de fato, descritiva e mentalista. Esta foi na verdade a hipótese de trabalho inicial de minha pesquisa. Ela foi logo abandonada, entretanto, sendo substituída por uma segunda hipótese, a saber, a de que haveria duas disciplinas merecendo o nome de Lógica, ambas mentalistas, uma descritiva - que vou chamar Lógica Naturalizada ou, em outros contextos, Lógica psicologista -, outra normativa - que vou chamar de Lógica Tradicional. A Lógica Naturalizada é parte da Ciência Cognitiva, a Tradicional corresponde ao que normalmente se entende por Lógica, simplesmente, num sentido amplo; ela engloba o Cálculo de Predicados de primeira ordem e ordens superiores, mais as lógicas complementares e não-clássicas ou alternativas. ${ }^{4}$

4. Esta segunda hipótese é uma simplificação. Em minha opinião, a melhor divisão do território de que estamos tratando é a definida pelas quatro seguintes teses:

1. A Lógica Tradicional é uma disciplina descritiva, e não normativa. Ela compartilha com a Matemática a característica de ter por objeto o estudo de sistemas formais, e pode ser considerada ou como parte desta, ou como uma disciplina independente, mas tendo natureza muito semelhante à da Matemática.

2. O conteúdo normativo que Frege atribuía à Lógica, ou seja, a prescrição de como devemos pensar, pertence a uma disciplina que pode ser chamada Teoria da Racionalidade. A Teoria da Racionalidade engloba uma parte que correspondeà Lógica Tradicional, porém também outras correspondendo à Lógica Indutiva, à Teoria da Decisão e à Metodologia Científica. É à Teoria da Racionalidade que cabe se pronunciar sobre a questão das lógicas alternativas. O nível de precisão nos conceitos, principios e argumentações da Teoria da Racionalidade que se pode esperar é muito inferior ao da Lógica Tradicional - caracterizada como o estudo dos sistemas formais - e 
É possível agora indicar o que pretendo - e o que não pretendo - com este trabalho. O que pretendo é refutar os argumentos antipsicologistas de Frege considerados na qualidade de objeções à TESE DUALISTA enunciada acima. Vejamos o que não pretendo.

Para fazer justiça a Frege seria necessánio evidentemente avaliar seus argumentos em relação a seu alvo original, ou seja, as várias teorias psicologistas que estavam sendo aventadas na segunda metade do século passado. O primeiro passo nesse sentido seria fazer um estudo dessas teorias. Este seria um trabalho em História da Filosofia, uma pesquisa que ainda está para ser realizada. Alguns dos comentánios mais recentes à obra de Frege (por exemplo, os de Sluga, 1980, e Currie, 1982) procuram caracterizar e traçar as raízes históricas das idéias psicologistas, mas nenhum deles levou a cabo um levantamento sistemático a respeito das obras e autores aos quais Frege faz referências específicas. Esta tarefa é dificultada pelo fato de que, devido à própria vitória de Frege, toda esta tradição psicologista caiu num pronunciado esquecimento; muitas obras relevantes são mesmo de difícil acesso. Uma das coisas que não pretendo fazer é este levantamento: apesar de sua importância histónica, ele é irrelevante para meus propósitos, que estão ligados ao presente, à Lógica psicologista que se tenta fazer hoje, como parte do desenvolvimento da Ciência Cognitiva. Não pretendo também discutir o psicologismo na Matemática. Embora este seja um tópico dos mais importantes na obra de Frege, e embora apresente muitos aspectos em comum com o psicologismo em Lógica, ele envolve também questões mais técnicas de Filosofia da Matemática, de tal modo que seu estudo representaria um outro trabalho de envergadura no mínimo da mesma ordem de grandeza que a do presente.

A Lógica psicologista combatida por Frege foi caracterizada acima como sendo descritiva e mentalista. Os argumentos de que ele se vale dividem-se naturalmente em duas classes, conforme tenham um ou outro desses aspectos como alvo. $\mathrm{Na}$ verdade, os dois aspectos são independentes, e o reconhecimento disso constitui a operação analítica primordial para a discussão das questões relacionadas ao psicologismo em Lógica.

Nos escritos de Frege, entretanto, não se encontra essa distinção, nem explícita nem implicitamente. Vejamos por que. À descritividade, Frege opõe a normatividade; ao mentalismo, o platonismo. Da independência das duas dimensões em questão segue-se que se deve ponderar também as idéias de uma Lógica mentalista e normativa e platônica e descritiva. Nenhuma dessas duas possibilidades é discutida

esta é uma das razões para a proposta de divisão territorial que defendemos.

3. A Lógica Tradicional concebida desta maneira constitui-se numa linguagem em que se expressam as proposições tanto da Teoria da Racionalidade quanto da Lógica Naturalizada; a relação é análoga à que a Matemática tem com a Física e muitas outras disciplinas.

4. Os processos que se podem abordar nos termos da Lógica Tradicional constituem apenas uma pequena parte dos processos que podem ser estudados, ou de uma postura normativa, na Teoria da Racionalidade, ou de uma postura descritiva, na Lógica Naturalizada. Em outras palavras: se a Lógica Tradicional fosse caracterizada como uma teoria dos processos de pensamento, ela seria uma teoria apenas de alguns poucos tipos de processos de pensamento. A versão caricatural da tese é: o conteúdo normativo da Lógica Tradicional prescreve como devemos pensar apenas quando estamos fazendo Matemática. 
por Frege, ele parece tomar implicitamente como princípio que uma Lógica mentalista é necessariamente descritiva e vice-versa. A existência de uma Lógica mentalista e normativa é parte da tese central deste trabalho; quanto à idéia de uma Lógica platônica e descritiva, mostraremos mais tarde que é mais sustentável do que a da Lógica platônica e normativa de Frege: em outras palavras, o platonismo combina melhor com a descritividade do que com a normatividade.

Além de muito importante, esta análise do psicologismo em dois componentes parece-nos bastante óbvia e natural. Apesar disso ela também não se encontra com o destaque que merece nos escritos dos comentadores de Frege - o que provavelmente se explica pela já mencionada pouca atenção que tem recebido a questão do psicologismo nesta literatura. Esta é, portanto, uma das contribuições que acreditamos estar trazendo ao debate com este trabalho.

Daqui por diante apresentarei um sumário - não mais que um índice comentado - do trabalho que planejo escrever como veículo para os resultados da pesquisa a que venho me dedicando. Tudo o que foi dito até agora fará parte da Introdução do artigo; depois dela terá início a discussão propriamente dita dos argumentos antipsicologistas de Frege. Em conformidade com as observações acima, o primeiro princípio organizador será sua separação em dois grupos, de um lado os que têm a descritividade como alvo, de outro os que atacam o mentalismo.

A argumentação de Frege contra a idéia de uma Lógica descritiva é válida somente em relação a colocações que reconhecem apenas uma Lógica - como era o caso, em verdade, de pelo menos algumas das obras por ele criticadas. Quando se adota a tese dualista enunciada acima - a de que existem duas Lógicas, uma descritiva e outra normativa - é fácil mostrar que todos os argumentos de Frege caem por terra - o que talvez não seja surpreendente. Desta maneira, o objetivo principal desta parte do artigo não é tanto estabelecer este resultado, mas sim mostrar a plausibilidade da tese dualista. Isto se faz por meio de comparações, primeiro com a Ética, em contraposição com a Antropologia e a Sociologia, segundo com a Lingüística. A comparação com a Lingüística é a mais explorada, pois sustenta a extrapolação da distinção chomskyana entre competência e desempenho (competence and performance) para os domínios da Lógica. Esta extrapolação é a base para a caracterização de uma das possíveis vertentes da Lógica Naturalizada, a que atribui a ela o objetivo de estabelecer uma teonia da competência lógica - por analogia com a Gramática enquanto teoria da competência lingüística. Esta concepção é desenvolvida por John Macnamara em seu recente $A$ border dispute: the place of logic in psychology.

Na parte seguinte do artigo discutem-se os argumentos antimentalistas de Frege Uma característica importante deles é a amplitude de seu alcance: se válidos, eles implicariam a impossibilidade não apenas de uma Lógica mentalista, mas de qualquer psicologia não-behaviourista. Nossa discussão terá, portanto, vários pontos de contato com o debate mais geral que se desenvolve atualmente a respeito dos fundamentos da Ciência Cognitiva. 
A parte seguinte trata do platonismo - a alternativa de Frege ao mentalismo. Recapitulam-se aí várias objeções já bem - conhecidas ao platonismo, e mostra-se ao que me consta, o que ainda não foi feito - a dificuldade de conciliar o platonismo com a concepção normativa da Lógica, isto como parte da argumentação cujo objetivo é demonstrar que o mentalismo é a fundamentação que convém tanto à Lógica descritiva - a Lógica Naturalizada - quanto à Lógica normativa.

OLIVEIRA, M. B. de. Logic and cognitive science: psychologism fights back. Trans/Form/Ação, São Paulo, v. 15, p. 123-130, 1992.

- ABSTRACT: The aim of the paper is to present the historical context and the motivation of an investigation still in progress, together with a sketch of some of its results. It starts with a brief description of the nature and history of cognitive science. The relation of cognitive science to logic is then considered, from which consideration a conception of logic as a descriptive and mentalist discipline emerges. Such conception clashes with Frege's antipsychologism. The purpose of the investigation is to refute Frege's arguments, considered as objections to the view that there are two logics, both mentalist, one descriptive and one normative.

- KEYWORDS: Logic; cognitive science; psychologism; Frege; normativeness; mentalism; platonism.

\section{Referências bibliograficas}

CHURCHLAND, P.M. Matter and consciousness: a contemporary introduction to the philosophy of mind. Cambridge (Mass.): The MIT Press, 1984.

CURRIE, G. Frege: an introduction to his philosophy. Brighton (Inglaterra): Harvest Press, 1982.

FREGE, G. Philosophical writings. Ed. P. Geach e M. Black. Oxford: Basil Blackwell, 1977.

GARDNEN, H. The mind's new science: a history of the cognitive revolution. New York: Basic Books, 1985.

GIEDYMIN, J. Empiricism refutability, rationality. In: LAKATOS, I., MUSGRAVE, A., comp. Problems in the philosophy of science. Amsterdam: North-Holland, 1968. p. 67-78.

HAACK, S. Philosophy of logics. Cambridge: Cambridge University Press, 1978.

MACNAMARA, J. A border dispute: the place of logic in psychology. Cambridge (Mass.): The MIT Press, 1986.

PIATTELLI-PALMARINI, M. Teorias da linguagem, teorias da aprendizagem: o debate entre Jean Piaget e Noam Chomsky. São Paulo: Cultrix/Edusp, 1983.

QUINE, W.V.O. Epistemologia naturalizada. Em Ryle,Strawson, Austin, Quine. São Paulo: Abril Cultural, 1981. (Os Pensadores)

QUINE, W.V.O. Roots of reference. La Salle (Ill.): Open Court, 1974.

QUINE, W.V.O. Word and object. Cambridge (Mass.): The MIT Press, 1960.

SLUGA, H. Gottlob Frege. Oxford: Basil Blackwell, 1980. 